\title{
HEAT TRANSFER ENHANCEMENT IN TURBULENT DRAG REDUCING SURFACTANT SOLUTIONS BY AGITATED HEAT EXCHANGERS
}

\author{
Maxson A.J., Watson, L.J., Karandikar, P.S., and Zakin, J.L.* \\ * Author for correspondence \\ Department of Chemical and Biomolecular Engineering, \\ The Ohio State University, \\ Columbus, OH 43210, USA, \\ E-mail: zakin.1@osu.edu
}

\begin{abstract}
Drag reducing solutions can reduce turbulent pressure loss by nearly $90 \%$ and can decrease pumping energy requirements and increase flow rates in fluid flow systems. Unfortunately, drag reduced flow is accompanied by lower convective heat transfer coefficients, which is undesirable in district heating and cooling systems, heated tube bundles for undersea petroleum production, and other recirculating heat transport systems.

In this study, three different rotating agitators were installed inside the inner tube of a concentric tube heat exchanger to enhance heat transfer in a surfactant drag reducing solution. An earlier mathematical model for heat transfer in scraped surface heat exchangers was adapted for this application so that the effectiveness of agitators with different geometries could be compared quantitatively. In addition, an enhancement efficiency factor was defined to compare power efficiency with previous methods. It was found that agitation can increase the inner heat transfer coefficient to exceed that of pure water; heat transfer reduction compared to water was reduced from $60 \%$ to $-20 \%$. In addition, the enhancement can be more energy-efficient than that of previously studied static mixers.
\end{abstract}

\section{Introduction and Background}

It was discovered in the 1930's and 1940's that introducing certain additives into a flowing liquid can reduce turbulence and decrease pressure loss [1] [2] [3]. This phenomenon is called drag reduction (DR), and solutions containing these additives are called drag reducing solutions.

There are two common types of DR additives: high molecular weight polymers and surfactants. When high molecular weight polymer DR additives are exposed to high mechanical shear (e.g. in pumps), the polymer chains are broken down and the DR behavior is permanently lost [4]. On the other hand, surfactant DR solutions are not permanently damaged because their worm-like micelle (WLM) structures are self-associating. If the WLMs are broken up by high shear they simply re-associate later, and the reassembly process can take just seconds [5]. For this reason, surfactant DR additives are suitable for use in recirculating systems, but polymer DR additives are not.

\section{NOMENCLATURE}

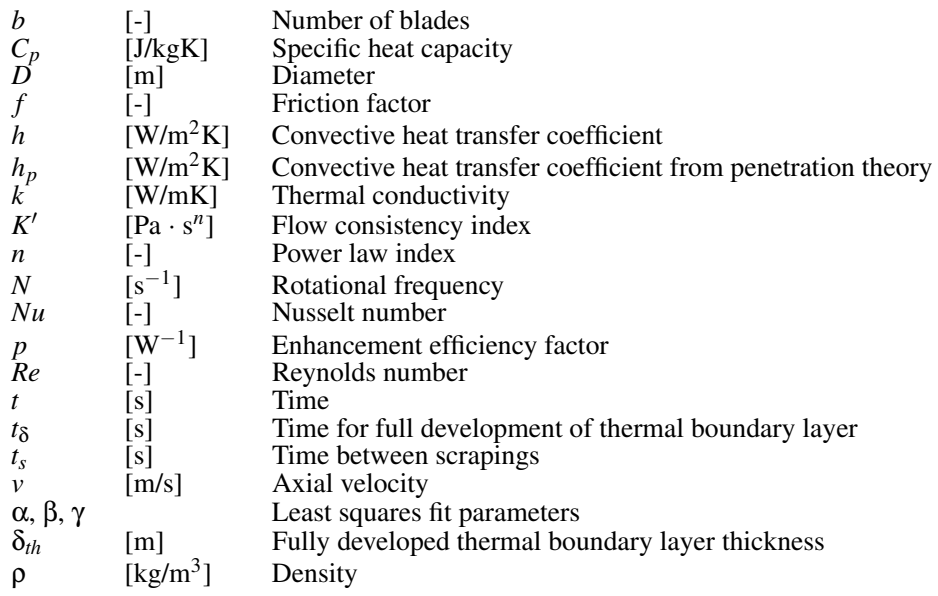

The exact mechanism by which DR additives reduce turbulent pressure loss is not fully understood. It is known, however, that the flow of DR solutions lacks some of the features of turbulent flow. Studies have shown that radial turbulence intensities are greatly reduced in DR flow [6], and it is accepted that this suppression of radial turbulence results in the reduced pressure loss [7].

The decrease in radial mixing as well as a thickened wall sublayer [8] in DR flow results in much lower convective heat transfer coefficients, so heat transfer in DR solutions is poor [9]. This reduction of heat transfer coefficients is called heat transfer reduction (HTR). Research has shown that the amount of HTR is always more than the amount of DR [10], and HTR can approach $90 \%$ [11].

DR is quantified as the percent decrease in the friction factor compared to the pure solvent at the same Reynolds number. For convenience of comparison with pure solvent flows, the thermophysical properties are taken to be the same as the solvent (water in this case). 


$$
D R \%=\frac{f_{\text {water }}-f_{\text {measured }}}{f_{\text {water }}} \cdot 100 \%
$$

Similarly, HTR is measured as the percent decrease in the Nusselt number compared to the pure solvent at the same Reynolds number, again using the thermophysical properties of the solvent.

$$
H T R \%=\frac{N u_{\text {water }}-N u_{\text {measured }}}{N u_{\text {water }}} \cdot 100 \%
$$

\subsection{Applications}

In recirculating heat transport systems, pumping energy could be saved by the introduction of surfactant DR additives. DR solutions have been used in district heating and cooling systems [12] and heated undersea tube bundles for oil production [13].

Despite the pumping energy savings and flow rate increases, surfactant DR solutions are not often used in heat transport systems. This is partly due to the environmental toxicity of many surfactant DR solutions (which is another active area of research [14]) and partly because of the HTR effect which may render existing heat transfer equipment inadequate. For this reason there is interest in finding ways of enhancing heat transfer ability during heat transfer operations without sacrificing energy efficiency.

\subsection{Previous Methods for Enhancing Heat Transfer}

Many heat transfer enhancement methods have been explored in heat exchangers, and some of these methods have been studied in systems containing surfactant drag reducing solutions. Usually, these are passive mechanical devices. Also called "turbulators," examples include spring coils, twisted tapes, alternating helical mixers, honeycombs, and meshes.

When used with DR solutions, there are two possible useful effects of these devices. First, placed near the entrance of the heat exchanger, they can exert a sufficiently high shear stress to temporarily break down the surfactant WLMs, resulting in non-DR behavior for a short time. Until the WLMs self-repair, turbulence and heat transfer are significantly increased [15]. Secondly, most of these devices produce forced radial mixing in their immediate vicinity. This increases the convective heat transfer coefficient locally, but because the static mixing device is typically positioned only at the entrance of the heat exchanger, this effect is usually very small. Disadvantages of these devices include large pressure losses and the possibility that DR WLMs can reassemble before exiting the heat exchanger.

Other enhancement methods explored recently include a high efficiency vortex generator (HEV) [16], sonication [17], in which enhancement was modest and energy requirements were high, and photosensitive switchable drag reducing solution [18] which was deemed impractical for large scale application because of the need to develop new high intensity ultraviolet irradiation equipment.

\subsection{Agitated Heat Exchangers}

One common way to enhance heat transfer within heat exchangers for high viscosity fluids and processes where walls may be coated by scaling, sediment, or crystal formation is to use scraped surface heat exchangers (SSHEs). These commerciallyavailable agitated heat exchangers contain rotating or reciprocating shafts which repeatedly scrape the walls and increase mixing. Like in high viscosity fluids, turbulent mixing is absent in DR flow, so we hypothesized that SSHEs could be effective for enhancing heat transfer in DR solutions.

Though SSHEs have been studied extensively, and a number of correlations are reported in literature, nearly all are for laminar flow in viscous fluids. De Goede and de Jong have provided an excellent summary of the theoretical background, and they developed a correlation for turbulent flow in low viscosity fluids at high axial velocities [19].

\section{Materials and Methods}

\subsection{Agitator Designs}

In this study we tested three different designs of rotating agitators, based on common SSHE designs, in order to test the effect of agitation in the inner tube of a concentric tube heat exchanger. All three agitators were designed to increase mixing and enhance heat transfer without relying on the destruction of WLMs in surfactant drag reducing solution flows. It was expected that, since WLM destruction requires energy, non-destructive mixing methods would be more energy efficient.

Agitator A (Figure 1a) consisted of a single carbon fiber rectangular bar with a $8.433 \mathrm{~mm}$ by $3.175 \mathrm{~mm}$ cross-section. The clearance between the agitator and the inner wall of the inner tube of the heat exchanger was a minimum (at the corners of the shaft) of $0.57 \mathrm{~mm}$. The bar ran the entire length of the heat exchanger $(91.44 \mathrm{~cm})$. Round rods $3.175 \mathrm{~mm}$ in diameter were embedded axially into both ends of the bar to allow for installation of bearings and connection to the motor.

Agitator B (Figure 1b) consisted of two $3.175 \mathrm{~mm}$ diameter round rods that ran the full length of the heat exchanger. To provide rigidity and maintain even spacing, the rods were separated by six evenly spaced $12 \mathrm{~mm}$ long by $3.175 \mathrm{~mm}$ diameter rod segments. The total width of the agitator was $9.779 \mathrm{~mm}$, leaving a minimum clearance between the agitator and the wall of $0.42 \mathrm{~mm}$. $3.175 \mathrm{~mm}$ diameter rods were installed axially (between the two parallel rods) at each end, to allow for installation of bearings and connection to the motor.

Agitator C (Figure 1c) consisted of a single $3.962 \mathrm{~mm}$ round shaft with seventy-two $1 \mathrm{~mm}$ diameter rods (pins) installed in holes drilled radially through the center shaft. These pins extended $3 \mathrm{~mm}$ from the shaft in each direction so that there was a minimum clearance from the wall of $0.37 \mathrm{~mm}$. All of the pins were installed in a single plane passing through the center axis of the shaft. The shaft and pins ran the entire length of the heat exchanger, and the shaft protruded from both ends for connection to the motor.

Each agitator was installed axially into the inner tube of the 


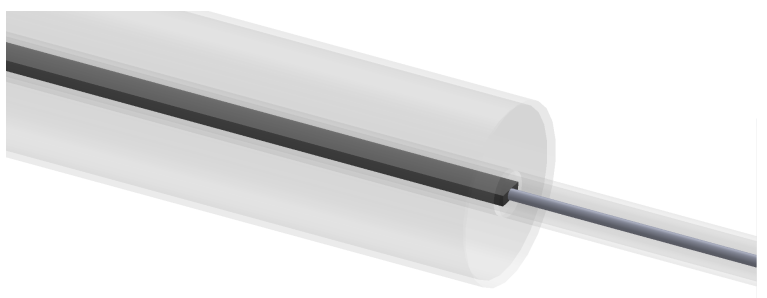

(a)

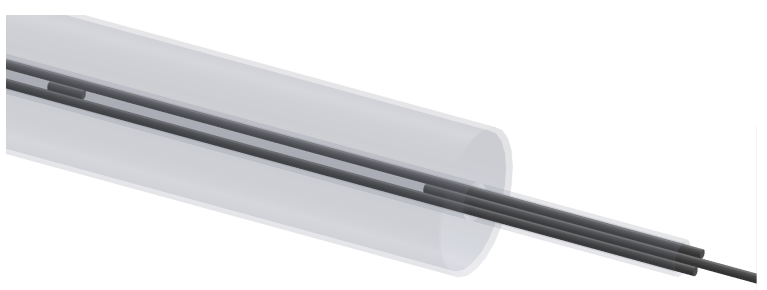

(b)

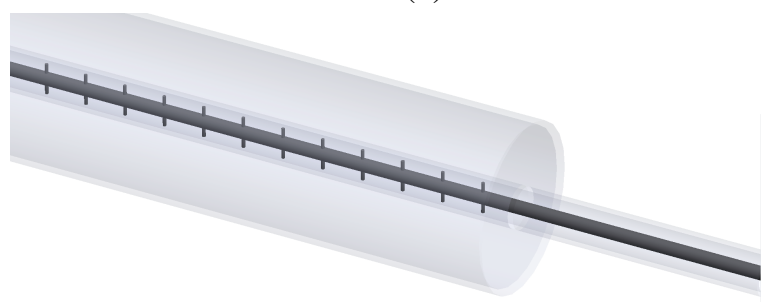

(c)

Figure 1. 3D models, Agitators A-C (a)-(c)

heat exchanger and retained via sealed stainless steel ball bearings at the ends of its shaft. Short pieces of vinyl tubing were sandwiched between the shaft and the inner bearing rings to ensure a watertight fit. Compression seals were made using rubber o-rings between the bearings and the tee fittings at the ends of the heat exchanger.

The speed of the 3/4 HP, three-phase electric motor was adjustable from 0-1800 rpm using an electronic motor speed controller. Speeds of 0, 300, 600, 900, 1200, 1500, and $1800 \mathrm{rpm}$ were tested. All three agitators were rotationally symmetric, so they were tested only in a clockwise direction of rotation. At maximum motor speed, the ratio of fluid linear velocity to shaft linear velocity ranged from approximately 1-4.

\subsection{Drag Reducing Solution}

The DR solution used in this study was Ethoquad O/12 (oleylbis(2-hydroxyethyl)-methylammonium chloride) from Akzo Nobel at concentrations of $2.5 \mathrm{mM}, 4.5 \mathrm{mM}$, and $6.5 \mathrm{mM}$ in distilled water. Sodium salicylate was added as a counterion at a molar ratio to the surfactant of $2: 1$. The solution was adjusted to a $\mathrm{pH}$ of 9 using sodium hydroxide.

\subsection{Flow Loop}

The flow loop consists of a $12 \mathrm{~m}$ long, $10.2 \mathrm{~mm}$ inner diameter stainless steel tube. An Oberdorfer N7000S15 gear pump is used to circulate the test fluid at flow rates of up to $6 \mathrm{gpm}$, corresponding to a Reynolds number of about 50,000. In this experiment the maximum Reynolds number was limited to about $4.5 \mathrm{gpm}$ by the ability of the sealed bearings at each end of the heat exchanger to hold pressure.

The fluid is pumped from a stainless steel storage tank containing ten liters of solution through the pressure drop test section and returns back through the heat exchanger test section. To maintain a steady temperature in the flow loop, the solution then passes through a second heat exchanger with process chilled water flowing in the shell side before returning to the storage tank. Hot water is supplied to the shell side of the test heat exchanger by a $1600 \mathrm{~W}$ heated water bath.

In the pressure drop test section, two 0-10 psi Omega PX-2300 pressure transmitters are used to measure pressure drop over two 1-meter tube sections. Another 0-100 psi differential pressure transmitter is used to measure pressure drop across the heat exchanger. This measurement is used to account for heat generation from viscous dissipation within the heat exchanger. Pressure readings are recorded using an Omega DaqBoard 2000 data acquisition system.

Two BAT-10 multipurpose thermometers from PhysiTemp, Inc., equipped with T-type thermocouples, are used to measure temperature differences across the tube and shell sides of the heat exchanger with an accuracy of $0.01{ }^{\circ} \mathrm{C}$. A single helical static mixer element is positioned just before the thermocouple at the outlet of the tube side to ensure uniform temperature distribution.

Flow rates of the chilled water, tube side, and shell side are measured using Toshiba LF-404 electromagnetic flow meters. The chilled water flow rate is controlled using a needle valve to maintain the desired inlet temperature on the tube side of the test heat exchanger. The flow rate on the tube side is controlled using a motor speed controller for the circulating pump. The flow rate on the shell side is controlled with a ball valve and maintained at 2 gpm.

\subsection{Measurement of HTR}

For each experiment, the order of measurements was randomized with respect to flow rate and rate of shaft rotation. The inlet temperature on the shell side was maintained at $50.0^{\circ} \mathrm{C}$, and the inlet temperature on the tube side was maintained at 24.5-25.0 ${ }^{\circ} \mathrm{C}$ as measured by the two BAT-10 multipurpose thermometers. When a steady state condition was reached, the thermometers were switched to differential mode, and readings were taken for both the tube and shell sides. In the case of fluctuations in the steady state temperature readings, observations were made for a period of 30 seconds, and the minimum and maximum values were averaged. Differential temperature measurements were corrected according to the National Bureau of Standards Monograph 125.

Prior to the experiment, experiments were performed with water on both sides of the heat exchanger to determine the value of the outer convective heat transfer coefficient using the Wilson Plot Method. Shell side conditions were kept constant when switching to DR solution on the tube side, enabling calcula- 
tion of the inner convective heat transfer coefficient. In addition, these measurements provided the values of $h_{\text {water }}$ needed for calculation of HTR. To a close approximation, $h_{\text {water }}$ was linear with Reynolds number in the range of flow rates tested. For all data points, the energy balance between the tube and shell sides agreed to within $8 \%$.

To enable direct comparison between agitators, the linear velocities used in calculating solvent Reynolds numbers were adjusted to account for the effect of agitator volume. The average cross-sectional area was reduced to $67 \%, 80 \%$, and $84 \%$ of the original value for Agitators $\mathrm{A}, \mathrm{B}$, and $\mathrm{C}$, respectively. The characteristic length used in calculating the Reynolds number was the inner diameter of the inner heat exchanger tube. Data presented here were based on analysis of measurements at adjusted Reynolds numbers from approximately 15,000 to 50,000 .

\subsection{Measurement of Power Input}

In order to analyze agitator energy efficiency for comparison with previous enhancement methods, it was necessary to measure the power input to the agitator shaft. To achieve this, a TorqSense E300 RWT electronic torque sensor was installed between the motor shaft and the agitator shaft. A series of experiments was performed at a concentration of $4.5 \mathrm{mM}$. Because of the difficulty associated with zeroing residual stresses in the bearings and couplings, three measurements of torque and rpm were recorded from the torque sensor in both clockwise and counterclockwise directions for each rate of rotation. The three pairs of measurements at each rpm were averaged, and the result showed a linear dependence of power input on rpm for all three agitators (Figure 2). Power consumption was independent of flow rate.

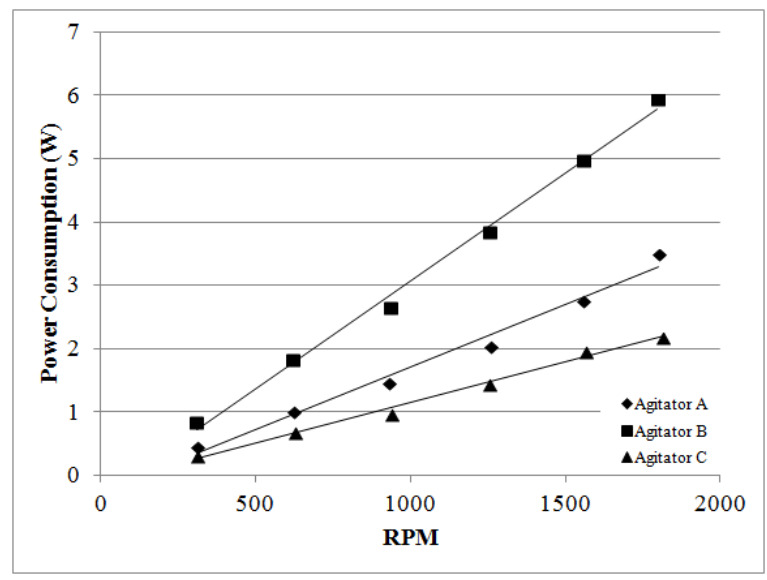

Figure 2. Power consumption vs. rpm by agitator

\subsection{Model Selection}

In order to quantify and compare agitator effectiveness, a mathematical model was needed. Kool [20] derived a model for heat transfer in scraped surface heat exchangers based on penetration theory. Penetration theory asserts that heat transfer is driven by unsteady state conditions and the lack of a developed thermal boundary layer. This leads to a square root dependence on rotational speed and no dependence on axial flow rate. This model cannot be applied in high axial flow rate scenarios without modifications. Various authors have developed empirical correlations to account for some of the limitations of penetration theory [21].

De Goede and de Jong [19] proposed that there exists a minimum $\mathrm{N}$ above which heat transfer is completely dominated by penetration theory. Below that minimum $\mathrm{N}$, heat transfer is governed by the time average contributions of the transient heat transfer immediately after a scraping action and the steady state heat transfer that takes place after the thermal boundary layer has reformed. This can be mathematically expressed as:

$$
h(N, R e)=\frac{1}{t_{s}}\left[\int_{0}^{t_{\delta}} h_{p} d t+\int_{t_{\delta}}^{t_{s}} h(R e) d t\right]
$$

where $h_{p}=2 \sqrt{\frac{k \rho C_{p}}{\pi t}}$ is the convective heat transfer coefficient predicted by penetration theory and $h(R e)$ is the non-scraped heat transfer coefficient. Upon integration and substituting $t_{s}=1 / n N$ this yields:

$$
2 b \sqrt{\frac{k \rho C_{p}}{\pi}} N \sqrt{t_{\delta}}+h(R e)-b N h(R e) t_{\delta}
$$

The time necessary for full development of the thermal boundary layer is:

$$
t_{\delta}=\frac{\delta_{t h}^{2} \rho C_{p}}{\pi k}
$$

In de Goede's derivation it is assumed that the flow was turbulent, in which case the thickness of the thermal boundary layer could be expressed as $\delta_{t h}=k / h$. Making these substitutions:

$$
h(N, R e)=\frac{b \rho C_{p} k}{\pi} \frac{N}{h(R e)}+h(R e)
$$

Although boundary layer phenomena in drag reducing surfactant solutions are not well understood, this assumption was kept for the following reasons. It has been shown that the hydrodynamic boundary layer thickness for drag reducing surfactant solutions increases for the first approximately 50 hydraulic diameters (the heat exchanger in our experiment was approximately 90 hydraulic diameters long) like a turbulent Newtonian fluid and then follows the equation for laminar Newtonian fluids [22]. It has also been shown that although turbulent intensities in drag reduced flow are dampened compared to water, in the near wall region they can approach or exceed that of water [23]. 


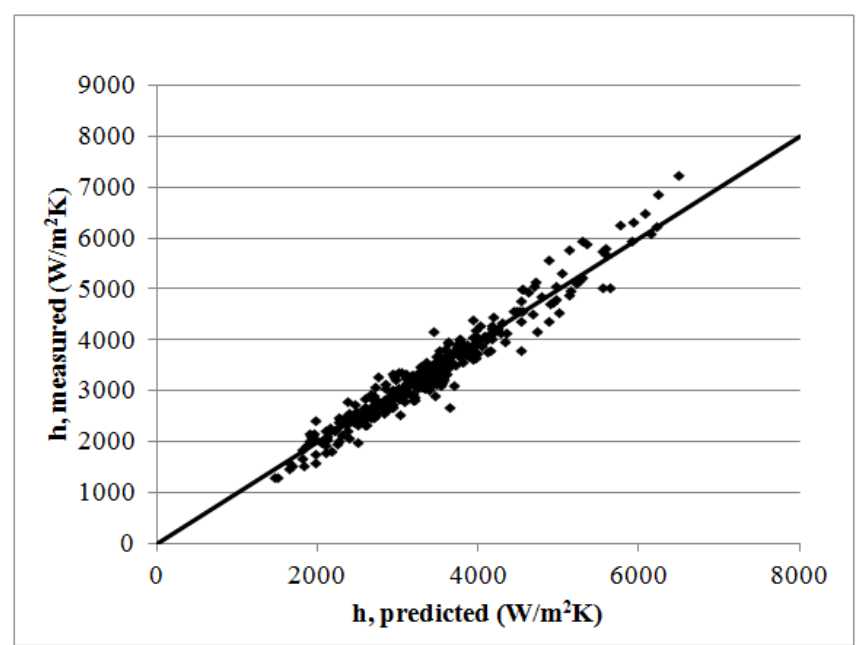

Figure 3. Comparison of all experimental values for $h$ to those predicted by the fitted models (all agitator types and concentrations)

Clapp [24] showed that heat transfer of power law fluids could be modeled with a modified Dittus-Boelter equation:

$$
N u=0.023(9350)^{0.8\left(1-\frac{1}{n^{n}}\right)}\left(\frac{D^{n} v^{2-n} \rho}{K^{\prime} 8^{n-1}}\right)^{\frac{0.8}{n^{n}}}\left[\frac{K^{\prime} C_{p}}{k}\left(\frac{8 v}{D}\right)^{n-1}\right]^{0.4}
$$

It can be seen that a power law index of 1, meaning a completely Newtonian fluid, results in the above equation simplifying to the Dittus-Boelter correlation. Due to the complex shear effects and flow geometries, $h(R e)$ was fitted as $h(R e)=\alpha R e^{\beta}$, a simplified version of Equation 7. Substituting this into Equation 6 and collecting coefficients we have:

$$
h(N, R e)=\frac{\gamma}{\alpha} \frac{N}{R e^{\beta}}+\alpha R e^{\beta}
$$

This was fitted by least squares for each concentration and agitator type. The exponents and coefficients were expected to vary between agitators and concentrations due to different geometries and the complex shear effects involved. It should be noted that the original model (Equation 8) does not contain any agitator geometry information other than number of blades, while in the new model $\gamma$ is expected to change with geometry. This difference is attributed to the fully turbulent flow present in the study by de Goede and de Jong [19], where the effect of the agitator is only to disturb the thermal boundary layer. Since DR solutions lack turbulent mixing, the agitator also has the effect of mixing the bulk flow. In this role the agitator geometry becomes significant.

\section{Results}

\subsection{Statistical Analysis}

The model was analyzed in the statistical analysis software program JMP. An analysis of variance was performed for each

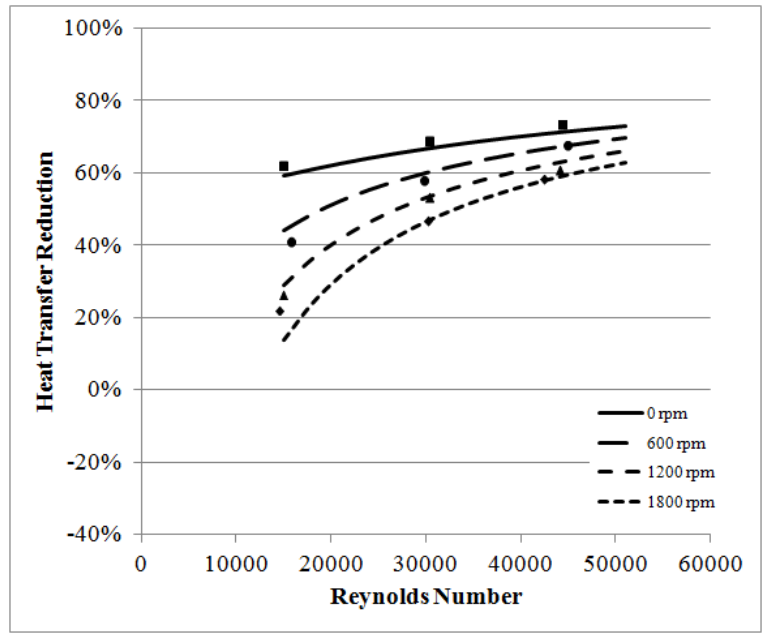

(a)

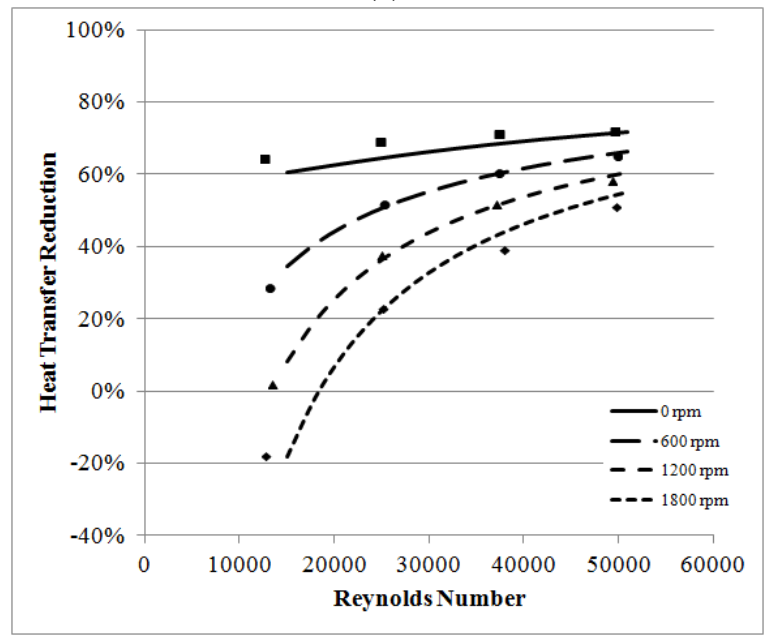

(b)

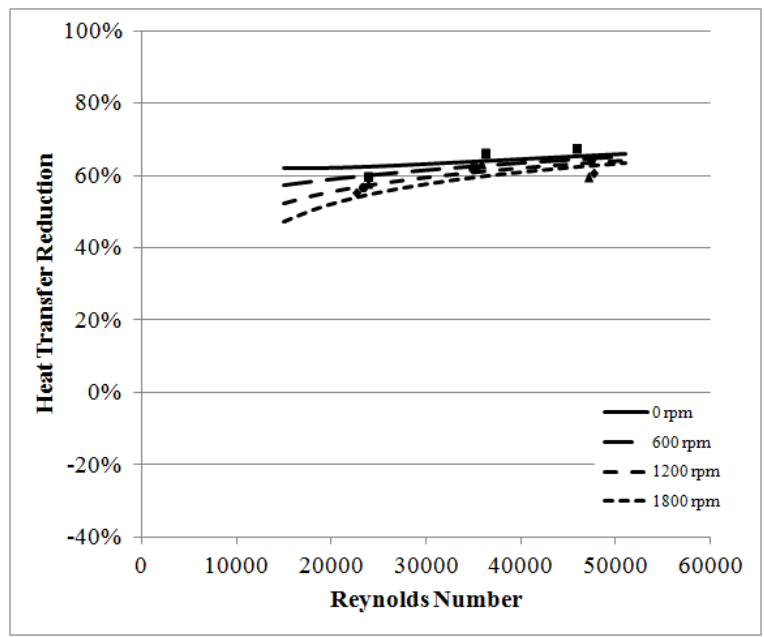

(c)

Figure 4. HTR curves from prediction expressions for Agitators A-C (a)-(c) at $4.5 \mathrm{mM}$. Experimental data points shown are: $0 \mathrm{rpm}$ (squares), $600 \mathrm{rpm}$ (circles), $1200 \mathrm{rpm}$ (triangles), and $1800 \mathrm{rpm}$ (diamonds). 
agitator type at each concentration, and p-values for the overall models were less than 0.0001 in all experiments. It was found that with a critical p-value of 0.05 , the factor $N / R e^{\beta}$ had significant effects for all agitators at all concentrations, with the exception of Agitator $\mathrm{C}$ at $2.5 \mathrm{mM}$ where the p-value was 0.69 . The factor $R e^{\beta}$ had significant effects at all concentrations for all agitators.

Prediction models using these two factors were developed in JMP for each agitator type. $R^{2}$ ranged from 0.89 to 0.97 , indicating that the model accurately describes the system behavior. Figure 3 shows the predicted and measured values for all agitators, concentrations, flow rates, and rates of agitator rotation.

HTR curves were generated using the prediction expressions; these are shown for the $4.5 \mathrm{mM}$ concentration in Figures $4 \mathrm{a}-4 \mathrm{c}$.

\subsection{Data Reduction}

In each prediction expression, the $\gamma$ coefficient on the $N / R e^{\beta}$ term indicates the relative effectiveness of the rotation of the agitator; a higher $\gamma$ indicates a greater effect of rotation. This coefficient was used for quantitative comparison of the agitator effectiveness. Normalized agitator performance factors are shown for all three agitators in Figure 5. In an unconstrained least squares fit, Agitator $\mathrm{C}$ had a near zero $\gamma$ at the $2.5 \mathrm{mM}$ concentration. Because $N / R e^{\beta}$ was found to be statistically insignificant in that trial, $\gamma$ was constrained to zero.

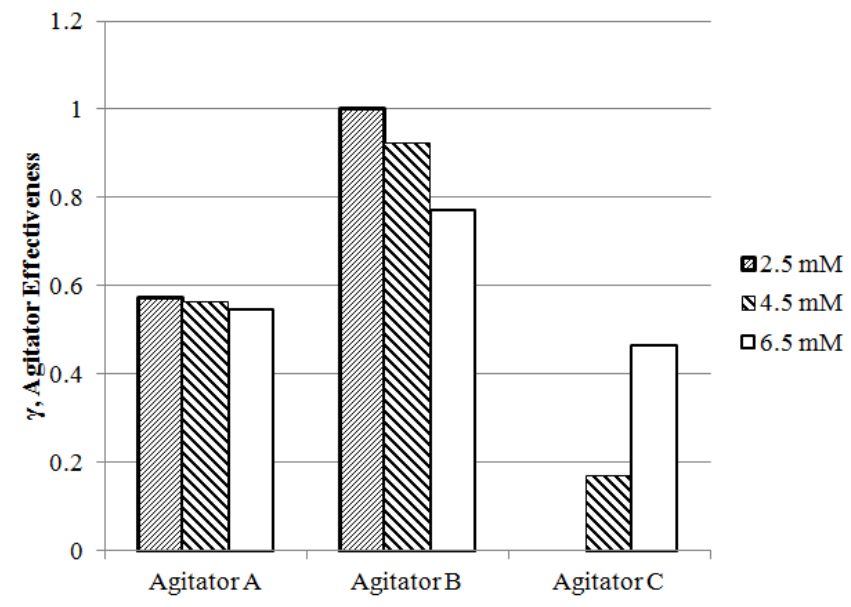

Figure 5. Comparison of normalized agitator effectiveness

To evaluate the heat transfer enhancement efficiency of the agitators and to compare with previous methods, an enhancement efficiency factor, $p$, was defined for the enhancement at a particular Reynolds number as follows:

$$
p=\frac{H T R_{\text {without device }}-H T R_{\text {with device }}}{\text { power consumption }}
$$

For comparison with previous methods at the same conditions tested in this study, the experiments in the earlier studies [15] [16] were repeated. Fortunately, the original equipment and supplies were still on hand from those experiments. For static mixers, power consumption was calculated from the pressure drop across the heat exchanger and the volumetric flow rate. For the agitated heat exchangers, power consumption was measured as described in Section 2.5. Results are shown in Figure 6.

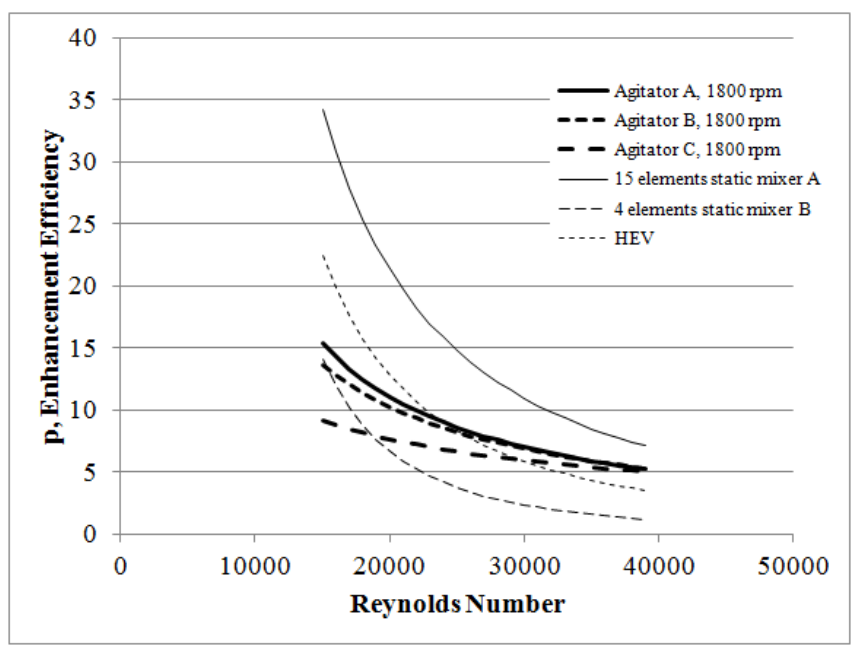

Figure 6. Comparison of enhancement efficiency factor, $p$, for various enhancement devices

\section{Conclusions}

1. Large decreases in HTR were achieved for surfactant DR solutions using agitated heat exchangers. At low axial velocities and high rates of rotation, negative values for HTR were obtained, indicating heat transfer coefficients greater than those for water with no agitator.

2. The agitated heat exchangers in this experiment reached lower HTR levels than any other previously reported HT enhancement method for DR solutions. Because they rely on turbulent mixing, WLM destruction methods cannot reach negative values, and can only reduce HTR to $0 \%$.

3. The model developed by De Goede and De Jong [19] was successful in describing the heat transfer enhancement produced by agitation in our DR system, and it should be generally applicable to all high axial velocity flows with or without turbulence.

4. Because power was provided by an external motor, no measureable pressure losses accompanied the HT enhancement. This is an advantage over static mixers, where the energy required for mixing comes from the flowing stream, requiring higher pressures upstream of the heat exchanger, which may be undesirable in some systems.

5. Agitator power consumption increased monotonically with agitator effectiveness, but due to the different mixing mechanisms of the agitators, no attempt to correlate power consumption with agitator effectiveness was made.

6. At high Reynolds numbers, the enhancement efficiencies of Agitators A and B were higher than those of Static Mixer B [15] and the HEV [16] from earlier studies. At higher Reynolds numbers, the efficiency of these agitators may also exceed that of the previously studied Static Mixer A [15]. 


\section{REFERENCES}

[1] F. Forrest and G.A.H. Grierson. Friction losses in cast iron pipe carrying paper stock. Paper Trade Journal, 92(22):3941, 1931.

[2] B.A Toms. Detection of a wall effect in laminar flow of solutions of a linear polymer. Journal of Colloid Science, 4(5):511-521, oct 1949.

[3] K. Mysels. Flow of thickened fluids, December 271949. US Patent 2,492,173.

[4] R. W. Paterson and F. H. Abernathy. Turbulent flow drag reduction and degradation with dilute polymer solutions. Journal of Fluid Mechanics, 43(04):689, oct 1970.

[5] Jiri Myska and Jacques L. Zakin. Differences in the flow behaviors of polymeric and cationic surfactant dragreducing additives. Industrial \& Engineering Chemistry Research, 36(12):5483-5487, dec 1997.

[6] Michael D. Warholic, Gavin M. Schmidt, and Thomas J. Hanratty. The influence of a drag-reducing surfactant on a turbulent velocity field. Journal of Fluid Mechanics, 388:1-20, jun 1999.

[7] P. S. Virk. Drag reduction fundamentals. AIChE J., 21(4):625-656, jul 1975.

[8] R. H. J. Sellin, J. W. Hoyt, and O. Scrivener. The effect of drag-reducing additives on fluid flow and their industrial applications, part 1: basic aspects. Journal of Hydraulic Research, 20(1):29-68, jan 1982.

[9] A. White. Heat transfer characteristics of dilute polymer solutions in fully rough pipe flow. Nature, 227(5257):486487, aug 1970.

[10] Guillermo Aguilar, Kazimir Gasljevic, and Eric F. Matthys. Asymptotes of maximum friction and heat transfer reductions for drag-reducing surfactant solutions. International Journal of Heat and Mass Transfer, 44(15):2835-2843, aug 2001.

[11] Jacques L. Zakin, Bin Lu, and Hans-Werner Bewersdorff. Surfactant drag reduction. Reviews in Chemical Engineering, 14(4-5), jan 1998.

[12] Hiromoto Usui and Takashi Saeki. Drag reduction and heat transfer reduction by cationic surfactants. J. Chem. Eng. Japan / JCEJ, 26(1):103-106, 1993.

[13] E. Sletfjerding, A. Gladsø, S. Elsborg, and H. Oskarsson. Boosting the heating capacity of oil-production bundles using drag-reducing surfactants. In International Symposium on Oilfield Chemistry. Society of Petroleum Engineers (SPE), 2003.
[14] I. Harwigsson and M. Hellsten. Environmentally acceptable drag-reducing surfactants for district heating and cooling. J Am Oil Chem Soc, 73(7):921-928, jul 1996.

[15] Yunying Qi, Yasuo Kawaguchi, Richard N. Christensen, and Jacques L. Zakin. Enhancing heat transfer ability of drag reducing surfactant solutions with static mixers and honeycombs. International Journal of Heat and Mass Transfer, 46(26):5161-5173, dec 2003.

[16] Haifeng Shi, Yi Wang, Wu Ge, Bo Fang, Jacob T. Huggins, Thaddaus R. Huber, and Jacques L. Zakin. Enhancing heat transfer of drag-reducing surfactant solution by an HEV static mixer with low pressure drop. Advances in Mechanical Engineering, 2011:1-10, 2011.

[17] Yunying Qi, Linda K Weavers, and Jacques L Zakin. Enhancing heat-transfer ability of drag reducing surfactant solutions with ultrasonic energy. Journal of Non-Newtonian Fluid Mechanics, 116(1):71-93, dec 2003.

[18] Haifeng Shi, Wu Ge, Hyuntaek Oh, Sean M. Pattison, Jacob T. Huggins, Yeshayahu Talmon, David J. Hart, Srinivasa R. Raghavan, and Jacques L. Zakin. Photoreversible micellar solution as a smart drag-reducing fluid for use in district heating/cooling systems. Langmuir, 29(1):102109, jan 2013.

[19] R. De Goede and E.J. De Jong. Heat transfer properties of a scraped-surface heat exchanger in the turbulent flow regime. Chemical Engineering Science, 48(8):1393-1404, 1993.

[20] J Kool. Heat transfer in scraped vessels and pipes handling viscous materials. Transactions of the Institution of Chemical Engineers, 36:253-258, 1958.

[21] H. Abichandani, S. C. Sarma, and D. R. Heldman. Hydrodynamics and heat transfer in liquid full scraped surface heat exchangers : a review, journal = Journal of Food Process Engineering. 9(2):121-141, apr 1986.

[22] Hiroshi Suzuki, Gerald G. Fuller, Tomoe Nakayama, and Hiromoto Usui. Development characteristics of dragreducing surfactant solution flow in a duct. Rheologica Acta, 43(3):232-239, may 2004.

[23] Zdenek Chara, Jacques L. Zakin, Miroslav Severa, and Jiri Myska. Turbulence measurements of drag reducing surfactant systems. Experiments in Fluids, 16(1), nov 1993.

[24] RM Clapp. International developments in heat transfer, part iii, 652-61; d-159. Technical report, D-211-5, ASME, New York, 1961. 